\title{
WRAPPER FEATURE SUBSET SELECTION FOR FEATURE EXTRACTION OF BONANG BARUNG SINGLE TONE CONVERSION INTO NUMERIC NOTATION
}

\author{
I. Wijayanto ${ }^{1}$, N. L. Hakim ${ }^{1}$, and A. Rizal ${ }^{1}$ \\ ${ }^{I}$ School of Electrical Engineering, Telkom University, Bandung, Indonesia
}

\begin{abstract}
Several researches have been done to study the characteristics of the Bonang Barung, one of Javanese gamelan music instruments. One of them is conversion of Bonang Barung single tone to numeric notation using Harmonic FFT as feature extraction and backpropagation artificial neural network (ANN) for classification. The tone detection accuracy result from previous research is $\mathbf{7 0 , 7 4 \%}$. In this research, we try to improve the detection result by searching the dominant features using wrapper feature subset selection (WFSS). Sequential forward selection (SFS) and sequential backward selection (SBS) are used as searching algorithm. The input of the system is a song recorded from a Bonang Barung then the detected tone is converted into numeric notation. From the experiment, WFSS-SFS produced 6 features with $86,4 \%$ accuracy while WFSS-SBS give a better result, it produced 13 features with $92,9 \%$ accuracy of tone detection.
\end{abstract}

Keywords: Bonang Barung; Wavelet Packet Decomposition; WFSS-SBS; WFSS-SFS.

\section{Introduction}

Javanese gamelan is a set of typical Javanese musical instrument handed down for generations. Bonang Barung is one of the Javanese gamelan musical instruments. Bonang Barung is a musical instrument made of iron, brass and bronze. They are typically hit with padded sticks (tabuh). Bonang Barung is a major head melodic instrument in the gamelan. This tool serves as pemurba song, which play a role as the course start-piece serving piece. Some research has been done to study the characteristics of the Bonang Barung. One of research has been done is conversion of Bonang Barung single tone to numeric notation using Harmonic FFT as feature extraction and Backpropagation Artificial Neural Network (ANN) for classification. By using tansig purelin activation function, learning rate $0.01,1000$ epoch and 20 hidden neurons as the properties of Backpropagation ANN, the best accuracy is $74.33 \%$.[1] The feature extraction method is used without considering the usage of the feature data.

Mostly, the high accuration result are obtained by using a better classification method at the expense of computation time. We try to improve the detection result by searching the dominant features using Wrapper Feature Subset Selection (WFSS). By using an appropriate feature we get: feature dimension reduction, better performance of the classifier and reduction of computation time. The data used are Bonang Barung single tones which obtained from direct recording saved in wav audio file format.

\section{Feature Extraction Based on Wavelet}

Wavelet has generated a tremendous interest in both applied and theoretical areas. Like Fourier

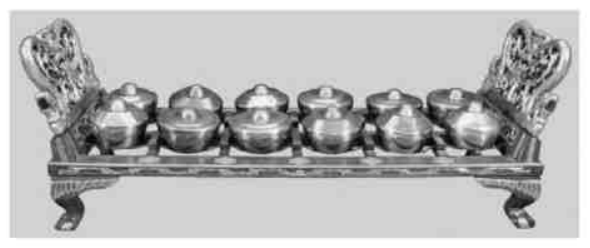

Figure 1 Bonang Barung

transform, the wavelet transform use inner product to quantify the similarity between an analyzing function and the source signal such as speech. In continuous wavelet transform, the analyzing function is a wavelet $(\psi)$, it compares the signal to shifted and compressed stretched versions of wavelet. Wavelet transform locked the variable of the signal in time and in scale. [2]

\subsection{Wavelet Packet Decomposition}

Wavelet packet decomposition is a wavelet transform which passed the source signal into more filters compared to discrete wavelet transform. Signal is divided into an approximation and a detail. The approximation then being divided again into an approximation and a detail, this process is repeated for $\mathrm{n}$-level decomposition. There are $\mathrm{n}+1$ and generate more than $2^{2^{n-1}}$ different ways to encode a signal. In discrete wavelet transform, each transformation level is calculated by passing approximation coefficients to both discrete time low and high pass quadrature mirror filters shown in Figure 3.

Mathematically 3 level wavelet decomposition can be written as: 
Wijayanto et al. / Journal of Measurements, Electronics, Communications, and Systems (2015) SP0115-01

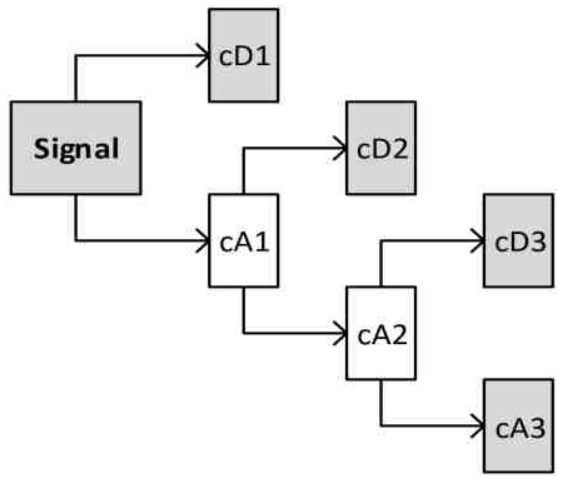

Figure 2 Wavelet Packet Decomposition

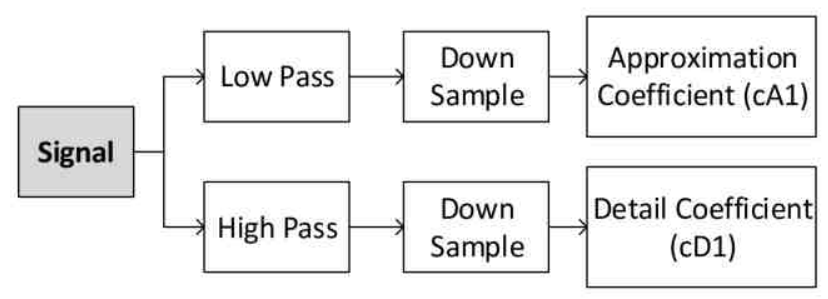

Figure 3 Wavelet Decomposition Process [2]

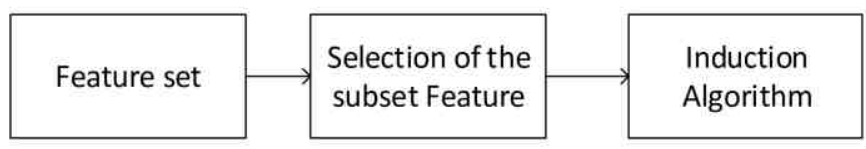

Figure 4 Filter approach for feature selection [4]

$$
\begin{aligned}
& X=c A_{1}+c D_{1} \\
& X=c A_{2}+c D_{2}+c D_{1} \\
& X=c A_{3}+c D_{3}+c D_{2}+c D_{1}
\end{aligned}
$$

$\mathrm{cA}_{1}$ and $\mathrm{cD}_{1}$ are obtained from the operation as described in Figure 2 and 3.

\subsection{Wrapper Feature Subset Selection (WFSS)}

Feature selection is a process that selects a subset of original features. Feature selection is one of the important and frequently used techniques in data preprocessing for data mining. Feature selection can reduce the dimension of a data, it select a subset of predictor variables to create a model. The minimization error prediction of a specific measurement is used in the criteria selection process so that the models can fit into different subsets.

Feature Subset Selection (FSS) is a process to determine the best subset for an atribute of a feature which reviewed from the contribution for class separability. This process reduces the data dimension and determines the feature which made the difference between classes and also does a better performance for the classifier. There are two techniques for FSS: [3]

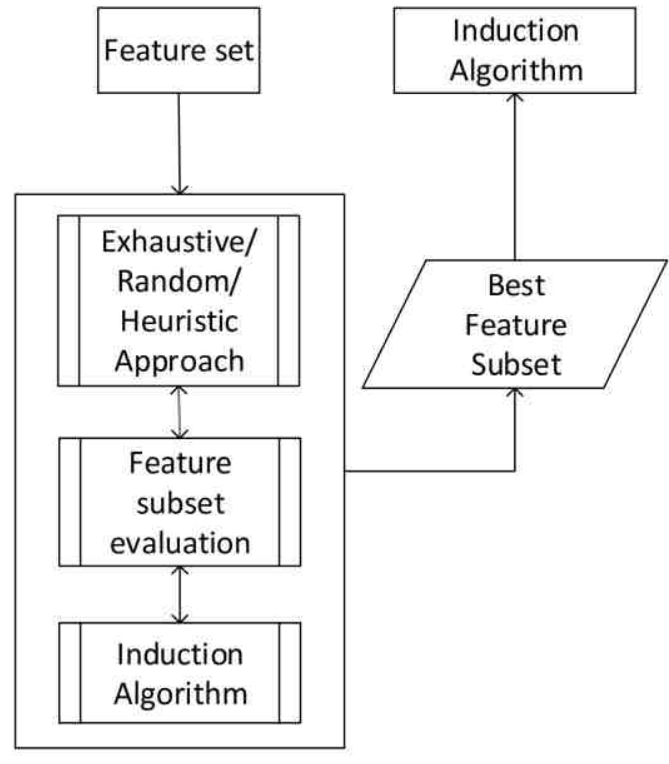

Figure 5 Wrapper Approach for Feature Selection [4]

1. Filter Approach for Feature Selection

The filter approach is self-sufficient from the induction algorithm and the computation is fast, scalable and being executed before the classification process. By using this method, the feature selection only done once and it can be used as the classifiers directly. [4]

\section{Wrapper Approach for Feature Selection}

Wrapper approaches use the classifier accuracy to do optimization from the feature selection process so that the accuracy can be increased. This model is dependent to the system classifier, because it use the classification method itself to determine the performance of the system features [4]. The weakness of this approach is the processing time. It takes longer time to process because every subset must be evaluated independently in the training process and in the classifier algorithm. [5, 6, 7]. Examples for wrapper technique is Sequential Feature Selection. This method has two variants: Sequential Forward Selection (SFS) and Sequential Backward Selection (SBS).

In SFS, the features are added to an empty candidate sequentially. Each features added is tested to measure the given effect to the classifier algorithm. The best feature result is chosen and combined with the next feature. This combined feature is tested again in the classifier algorithm and measure the result. The best result is being added again with the next feature, this process is repeated until several best accuracies obtained and does not decrease the criterion.

SBS algorithm works the opposite ways with SFS. Features are sequentially removed from a full candidate set. First, several $\mathrm{N}$ features are used to find the best accuracy, when 1 feature is removed and it is not give a huge effect for the accuracy, then it will be permanently deleted. The next step, from 
Wijayanto et al. / Journal of Measurements, Electronics, Communications, and Systems (2015) SP0115-01

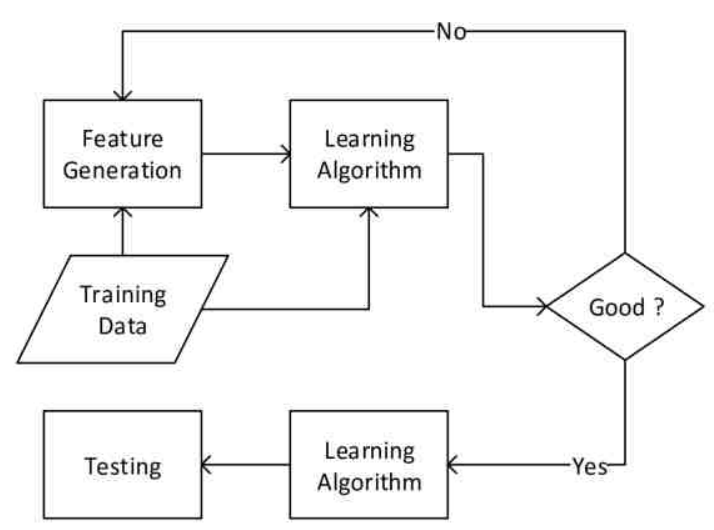

Figure 6 Wrapper Process [3]

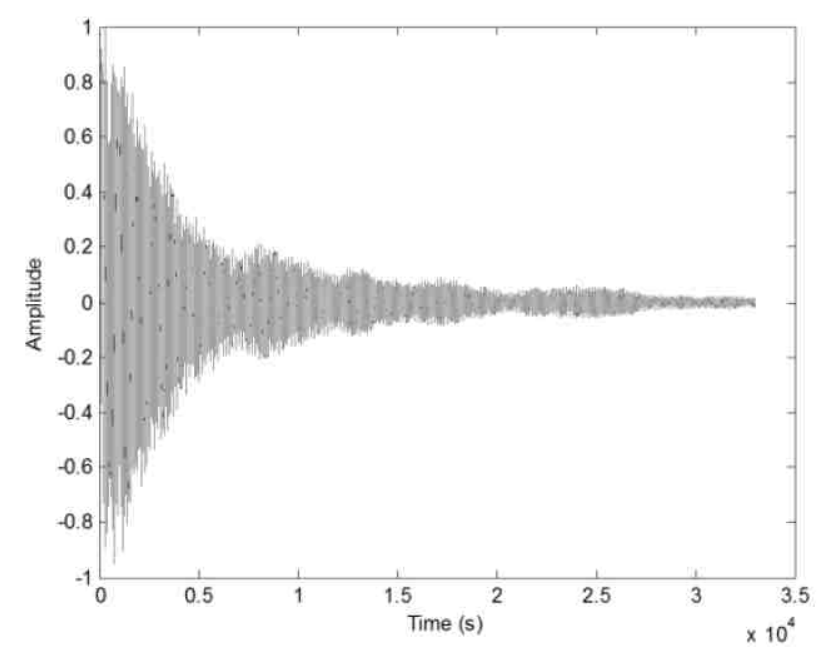

Figure 7 "Low Tones 1.wav" Time-Amplitude graph

the $\mathrm{N}-1$ feature, 1 feature is removed again, we get $\mathrm{N}-2$ feature tobe tested. If the removed feature did not give a huge effect for the accuracy, then it will be permanently deleted. This process is repeated until the removal of the next features reduces the accuracy significantly. [3]

The wrapper process in Figure 6 will reduce the number of features. The system only uses the features which give the significant result to the system accuracy.

\section{Analysis}

The first scenario done in this research used wavelet packet decomposition as feature extraction and the second scenario used WFSS as feature extraction. Backpropagation ANN used as the classifier. The result from this two scenario is compared.

The training data is 10 data for each class of tones, with total 140 training data. The testing data used 10 data for each class of tones and a recorded song with single tone stroke (nggamel).

\subsection{Feature Extraction}

One training data set consist of 7 low tones and 7 high tones. There are 10 sets of training data, with total 140 training data. From experiment, the average number of feature produced by each Bonang Barung single tone is 20 features.

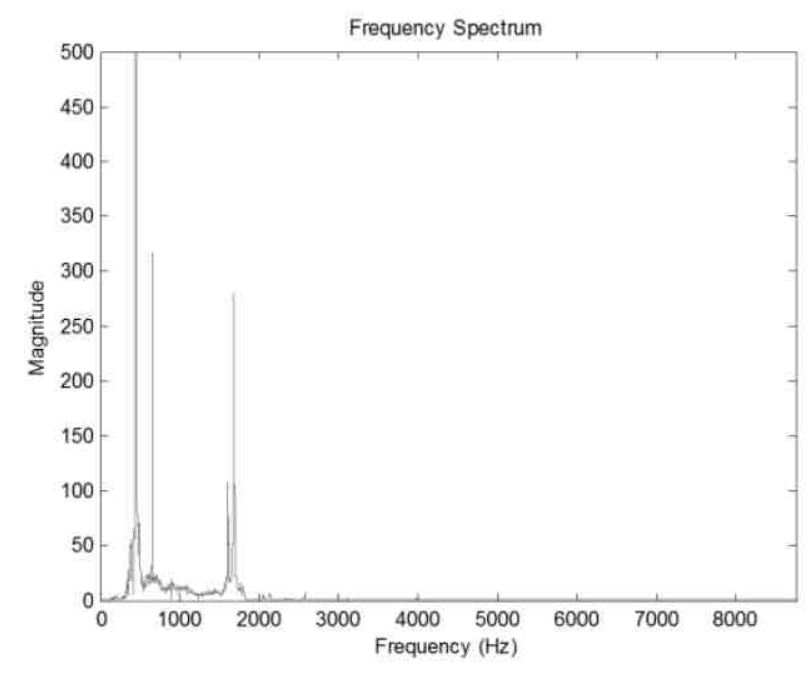

Figure 8 "Low Tones 1.wav" frequency spectrum

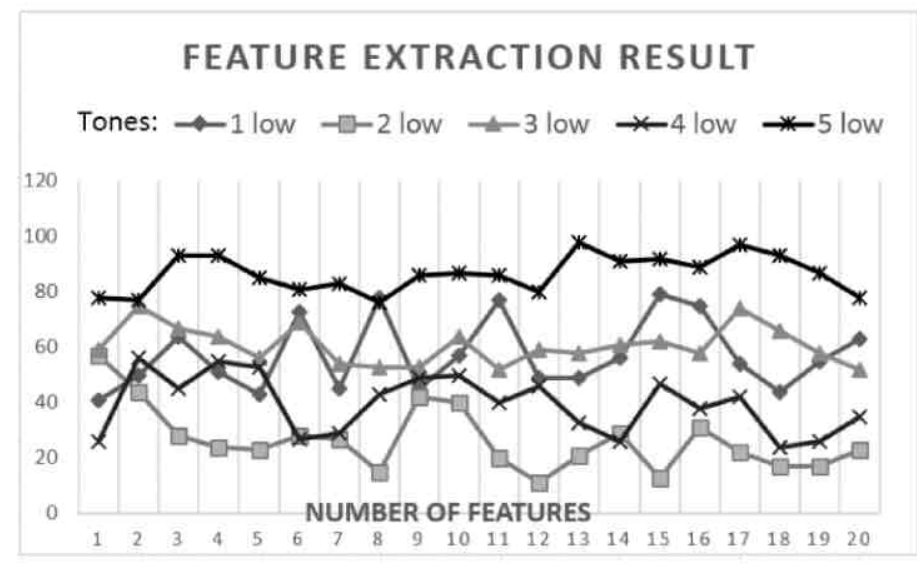

Figure 9 Feature Extraction Result Samples

\subsection{Classification and Detection wihout Feature Selection}

Backpropagation ANN is used for tone classification and detection. The parameters of Backpropagation ANN used are:

Epoch $\quad: 1000$

Hidden Neurons $\quad: 20$

Activation Func : Purelin

Learning Rate : 0.01

The result sample is shown in Table 1. From 140 sample data extracted by wavelet packet decomposition, we conduct a test using another 140 tones data to be detected and classified. From the testing, the result we can conluded that the accuracy of the system is

$$
(104 / 140) \times 100 \%=74.3 \%
$$

This result will be compared using the classification using feature extraction selected by WFSS. 
Wijayanto et al. / Journal of Measurements, Electronics, Communications, and Systems (2015) SP0115-01

Table 1 Detection Result using Wavelet Packet Decomposition as Feature Extraction

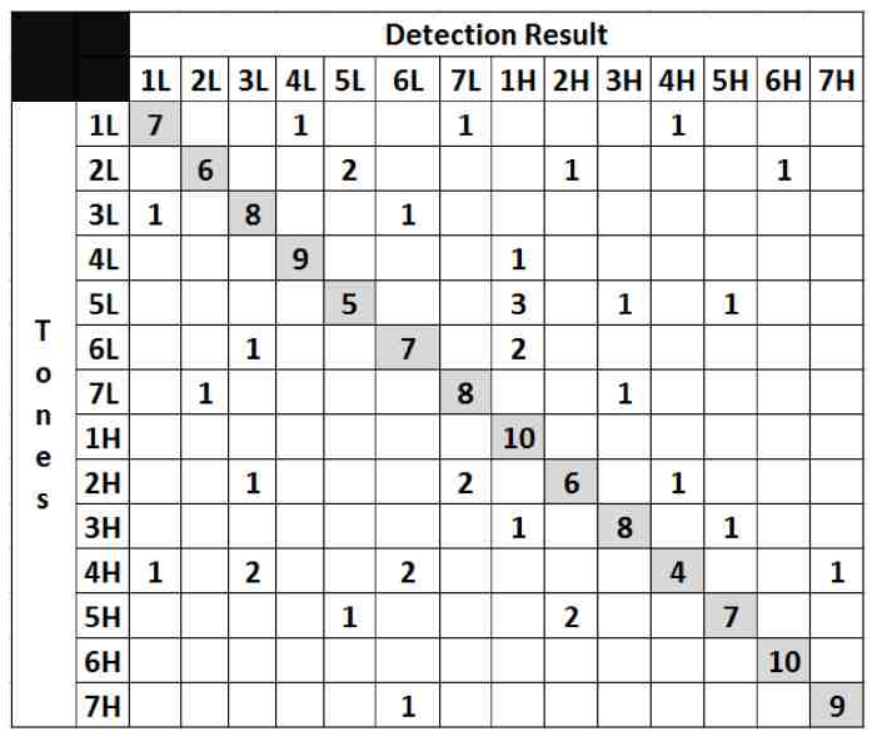

Table 2 Detection Result using WFSS-SFS as Feature Extraction

\begin{tabular}{|c|c|c|c|c|c|c|c|c|c|c|c|c|c|c|c|}
\hline & & \multicolumn{14}{|c|}{ Detection Result } \\
\hline & & 1L & 2L & 3L & $4 \mathrm{~L}$ & $5 L$ & $6 \mathrm{~L}$ & 7L & $1 \mathrm{H}$ & $2 \mathrm{H}$ & $3 \mathrm{H}$ & $4 \mathrm{H}$ & $5 \mathrm{H}$ & $6 \mathrm{H}$ & $7 \mathrm{H}$ \\
\hline \multirow{14}{*}{$\mathbf{T}$} & 1L & 8 & & & & & & 1 & & & & 1 & & & \\
\hline & $2 \mathrm{~L}$ & & 9 & & & & & & & 1 & & & & & \\
\hline & $3 \mathrm{~L}$ & 1 & & 8 & & & 1 & & & & & & & & \\
\hline & $4 \mathrm{~L}$ & & & & 9 & & & & 1 & & & & & & \\
\hline & $5 \mathrm{~L}$ & & & & & 8 & & & 1 & & 1 & & & & \\
\hline & $6 \mathrm{~L}$ & & & & & & 8 & & 2 & & & & & & \\
\hline & $7 \mathrm{~L}$ & & & & & & & 10 & & & & & & & \\
\hline & $1 \mathrm{H}$ & & & & & & & & 10 & & & & & & \\
\hline & $2 \mathrm{H}$ & & & & & & & 2 & & 7 & & 1 & & & \\
\hline & $3 \mathrm{H}$ & & & & & & & & 1 & & 9 & & & & \\
\hline & $4 \mathrm{H}$ & 1 & & 2 & & & & & & & & 7 & & & \\
\hline & $5 \mathrm{H}$ & & & & & 1 & & & & & & & 9 & & \\
\hline & $6 \mathrm{H}$ & & & & & & & & & & & & & 10 & \\
\hline & $7 \mathrm{H}$ & & & & & & 1 & & & & & & & & 9 \\
\hline
\end{tabular}

\subsection{WFSS Analysis}

The first experiment, SFS method is used to find the best features. From the simulation, we get 6 features which made a significant result, they are features number: $2,5,9,11,17$ and 19 . The tones classification and detection result are shown in Table 2. The accuration of the system is

$$
(121 / 140) \times 100 \%=86,4 \%
$$

From this experience, it is showed that from 20 features, there are 6 features which can made a significant result for increasing the accuration.

The second experiment, SBS method is used to find the best features. From the simulation we get 13 features which made a significant result, they are features number: $1,3,4,5,8,9,11,13,14,15,18,19$ and 20 .

The tones classification and detection result are shown in Table 3. The accuration of the, system is $(130 / 140) \times 100 \%=92,9 \%$
Table 3 Detection Result using WFSS-SBS as Feature Extraction

\begin{tabular}{|c|c|c|c|c|c|c|c|c|c|c|c|c|c|c|c|}
\hline & \multicolumn{14}{|c|}{ Detection Result } \\
\hline & & $1 \mathrm{~L}$ & $2 \mathrm{~L}$ & $3 \mathrm{~L}$ & $4 \mathrm{~L}$ & $5 \mathrm{~L}$ & $6 \mathrm{~L}$ & 7L & $1 \mathrm{H}$ & $2 \mathrm{H}$ & $3 \mathrm{H}$ & $4 \mathrm{H}$ & $5 \mathrm{H}$ & $6 \mathrm{H}$ & $7 \mathrm{H}$ \\
\hline \multirow{14}{*}{$\mathrm{T}$} & $1 \mathrm{~L}$ & 10 & & & & & & & & & & & & & \\
\hline & $2 \mathrm{~L}$ & & 9 & & & & & & & 1 & & & & & \\
\hline & $3 L$ & 1 & & 8 & & & 1 & & & & & & & & \\
\hline & 4L & & & & 9 & & & & 1 & & & & & & \\
\hline & $5 \mathrm{~L}$ & & & & & 10 & & & & & & & & & \\
\hline & $6 \mathrm{~L}$ & & & & & & 8 & & 2 & & & & & & \\
\hline & $7 \mathrm{~L}$ & & & & & & & 10 & & & & & & & \\
\hline & $1 \mathrm{H}$ & & & & & & & & 10 & & & & & & \\
\hline & $2 \mathrm{H}$ & & & & & & & 1 & & 9 & & & & & \\
\hline & $3 \mathrm{H}$ & & & & & & & & & & 10 & & & & \\
\hline & $4 \mathrm{H}$ & 1 & & & & & & & & & & 9 & & & \\
\hline & $5 \mathrm{H}$ & & & & & 1 & & & & & & & 9 & & \\
\hline & $6 \mathrm{H}$ & & & & & & & & & & & & & 10 & \\
\hline & $7 \mathrm{H}$ & & & & & & 1 & & & & & & & & 9 \\
\hline
\end{tabular}

Table 4 Tones Detection Result from Songs

\begin{tabular}{|c|c|c|c|c|}
\hline \multirow[t]{2}{*}{ Song } & \multirow{2}{*}{$\begin{array}{c}\text { Number of } \\
\text { Actual } \\
\text { Tones }\end{array}$} & \multicolumn{3}{|c|}{$\begin{array}{c}\text { The Number of Correctly Detected } \\
\text { Tones }\end{array}$} \\
\hline & & Wavelet & WFSS SFS & WFSS SBS \\
\hline Aja Lamis & 6 & 6 & 6 & 6 \\
\hline Ande-Ande Lumut & 13 & 10 & 11 & 13 \\
\hline Ayun-Ayun & 11 & 9 & 11 & 11 \\
\hline Gugur Gunung & 8 & 6 & 8 & 8 \\
\hline Kagok Semarang & 8 & 7 & 7 & 8 \\
\hline Lencir Kuning & 8 & 6 & 5 & 7 \\
\hline Manyar Sewu & 5 & 4 & 5 & 4 \\
\hline Pangkur & 14 & 9 & 9 & 12 \\
\hline Runtung & 14 & 10 & 10 & 13 \\
\hline Udan Mas & 13 & 11 & 9 & 11 \\
\hline
\end{tabular}

From the simulation using wraping technique, there are 13 significant features from 20 features extracted from Bonang Barung single tones using wavelet packet decomposition.

From the feature selection it is can be seen that from 20 features there are only 13 features which can differentiate each class significantly.

Compared to SFS, the SBS resulted more features, and better accuracy than SFS. The selection process in SFS is stopped because the accuracy is decreasing. This is happened because the best first algorithm force the system to halt the process when the accuracy is decreased. The weakness of this method is the computing time.

\section{Conclusion}

From the experiment, we can conclude that the wrapping process using SBS resulted a better tone detection. SBS also using fewer features compared with Wavelet Packet Decomposition. The features used by WFSS-SBS method are only 13 features while Wavelet Packet Decomposition used 20 features. The accuracy of the detection system using 
Wijayanto et al. / Journal of Measurements, Electronics, Communications, and Systems (2015) SP0115-01

WFSS-SBS is $92,9 \%$. It is better than WFSS-SFS, $86,4 \%$, and Wavelet Packet Decomposition, $74,3 \%$. The computation time of the detection system is reduced because the use of smaller number of features. It is better for the next research to use exhausted search method than best first method to find another possibilities of features combinations.

\section{References}

[1]. Listya Hakim. Nurina, Rizal.A, Wijayanto. Inung. 2015 Recognition and Analysis of Bonang Barung Single Tone Conversion into Numeric Notation Using Artificial Neural Network Backpropagation Algorithm. Telkom Univeristy. Bandung.

[2]. Krishnan. Vimal, Anto P. Babu. 2009. Features of Wavelet Packet Decomposition and Discrete Wavelet Transform for Malayalam Speech Recognition. International Journal of Recent Trends in Engineering, Vol.1 No.2

[3]. Rizal, A.. 2012. Wrapper Features Subset Selection in EKG Signal Feature Extraction using Wavelet Packet Decomposition. In Bahasa. Jurnal Informatika, Vol. 8 No.2. Bandung.

[4]. Karegowda. Asha Gowda, Jarayam. M.A, Manjunath. A.S. 2010. Feature Subset Selection Problem using Wrapper Approach in Supervised Learning. International Journal of Computer Applications. Vol.1 No.7.

[5]. M.Dash I, H. Liu2. March 1997. Feature Selection for Classification, Intelligent Data Analysis

(131156,www.elsevier.com/locate.ida)

[6]. Shyamala Doraisamy ,Shahram Golzari ,Noris Mohd. Norowi, Md. Nasir B Sulaiman, Nur Izura Udzir. 2008. A Study on Feature Selection and ClassificationTechniques for Automatic Genre Classification of Traditional Malay Music.

[7]. Y.Saeys, I.Inza, and P. LarrANNaga,. 2007. A review of feature selection techniquesin bioinformatics, Bioinformatics, 23(19), pp. 2507-2517.

[8]. Abonyi, Janos. (2014). Hinging hyperplane based regression tree identified by fuzzy clustering and its application. Veszprem : University of Veszprem.

[9]. Kohavi. Ron, George H. John. 1997. Wrappers for feature subset selection. Elsevier Science B. V

[10]. L. I. Kuncheva, Combining Pattern Classifiers: Methods and Algorithms. New York, NY: Wiley, 2004.

[11]. M.A. Bagheri, Gh. Montazer, and E. Kabir, A Subspace Approach to Error-Correcting Output Coding, Pattern Recognition Letters, vol. 34 , pp. $176-184,2013$
[12]. M.A. Bagheri, Q. Gao and S. Escalera, Rough Set Subspace Error Correcting Output Codes. Proc. IEEE International Conf on Data Mining, Brussels, Belgium, 2012

[13]. R. Polikar, Ensemble based systems in decision making. IEEE Circuits and Systems Magazine, vol. 6, pp. 21-45, 2006.

[14]. Rilling, G. 2008. On Empirical Mode Decomposition And Its Algorithms. Laboratoire de Physique (UMR CNRS 5672), 'Ecole Normale Sup'erieure de Lyon 46, all'ee d'Italie 69364 Lyon Cedex 07. France

[15]. Rizal, A., Jondri,. Hadiyoso, S. 2011. EKG Signal Recognition using Empirical Mode Decomposition (EMD), Wavelet Packet Decomposition and K-Mean Clustering. In Bahasa. Proceeding Konferensi Nasional Sistem Informatika 2011, STMIK STIKOM Bali, Denpasar

[16]. Rizal, A., Suryani, V. 2008. EKG Signal Recognition using Wavelet Packet Decomposition and K-Means Clustering. In Bahasa. Preceeding Seminar Nasional Teknologi Informasi (SNATI 2008), Universitas Islam Indonesia, Yogyakarta

[17]. Tompkins, W.J. 1993. Biomedical Signal Processing, Prentice Hall, New Jersey.

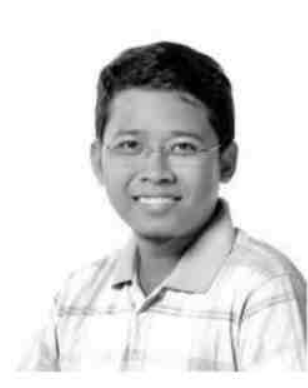

Inung Wijayanto received the B.S. and M.S. degree from Telecommunication Engineering, Telkom Institute of Technology, Bandung, Indonesia in 2008 and 2011 respectively. $\mathrm{He}$ is currently a Lecturer in School of Electrical Engineering Telkom University. His research interst includes, image processing, audio processing, image analysis, motion estimation and tracking, virtual reality and embedded system development.

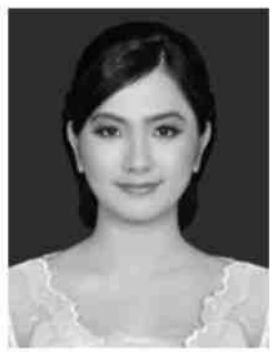

Nurina Listya Hakim received the B.S from Telecommunication Engineering, Telkom University, Bandung, Indonesia in 2015. Her research interest includes audio processing and audio recognition.

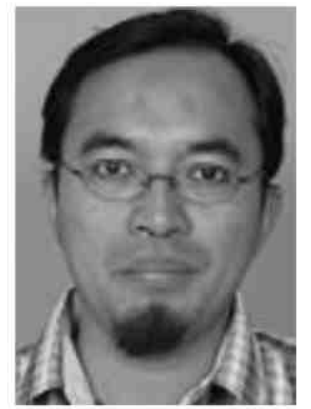

Achmad Rizal received B.S degree from Telecommunication Engineering, Sekolah Tinggi Teknologi Telkom in 2000. He also received M.S. degree from Biomedical Engineering, School of Elcectro and Informatics, Bandung Institute of Technology in 2006. He is now taking his Ph.D in Gajah 
Wijayanto et al. / Journal of Measurements, Electronics, Communications, and Systems (2015) SP0115-01

Mada University, Jogjakarta. His research interst includes biomedical signal processing, biomedical instrumentation, telemedicine system, neural networks applications, electrical instrumentation. 